(C2019, Elsevier. Licensed under the Creative Commons Attribution-NonCommercialNoDerivatives 4.0 International http://creativecommons.org/about/downloads 


\title{
High Velocity Impact on Composite Sandwich Panels with Nano-Reinforced
}

\section{Syntactic Foam Core}

\author{
Hamed Ahmadi ${ }^{*}{ }^{*}$, Gholamhossein Liaghat ${ }^{1,2}$, Sahand Chitsaz Charandabi ${ }^{3}$
}

${ }^{1}$ Department of Mechanical Engineering, Tarbiat Modares University, Tehran, Iran

${ }^{2}$ Department of Mechanical and Automotive Engineering, Kingston University, London, United Kingdom

${ }^{2}$ School of Mechanical Engineering, Coventry University, Coventry, United Kingdom

*Corresponding author: Mechanical Engineering Department, Tarbiat Modares University, Tehran, 1411713116, Iran. Tel.: +982182883391, Email Address: h_ahmadi@modares.ac.ir

\begin{abstract}
In this work, an experimental investigation of the high velocity impact resistance of syntactic foam core composite sandwich panel has been undertaken. The syntactic foams filled with ceramic microballoons of three different sizes and three different volume fractions. Also, to enhance the matrix strength of the foam core, some specimens reinforced with nano particles. The high velocity impact tests have been carried out using a light gas-gun and a $10 \mathrm{~mm}$ blunt-head steel projectile and the ballistic limit was measured. The Impact behavior and the failure mechanisms are thoroughly investigated and also the absorbed energy during projectile perforation was correlated to the damaged area of specimens. The test results show that the ballistic resistance decreases with increasing the volume fraction of microballoons and the panel with $40 \%$ volume fraction of microballoons has the highest specific perforation energy. Moreover, nano-reinforcing the syntactic foam core increased the ballistic limit velocity up to $10 \%$.
\end{abstract}

Keywords: Syntactic Foam; Ceramic Microballoon; High Velocity Impact; Ballistic Limit; Nanoreinforcing. 


\section{Introduction}

Syntactic foams are a type of lightweight polymer or metal (matrix) that filled with hollow particles (microballoons). The matrix can be made from a variety of materials such as metal, polymer or ceramic. In general, epoxy resins, polyesters, polyurethanes, silicones and several other polymers are used as matrix material while the microballoons have been made of glass, carbon, ceramic or polymers [1]. The data from literature show that the syntactic foams have improved properties relative to the pure matrix, e.g. excellent strength to weight ratio, low moisture absorption, enhanced thermal insulation, etc. These improvements have been made them attractive for engineering applications such as marine equipments [2], core of structural sandwich panels [3], components for aerospace [4] and automotive industry [5]. Reinforcing matrix by thin particle shells has several advantageous such as control over the shape, size distribution and volume fraction of particles. Consequently, a combination of matrix material, the size of the microballoon and material / filler volume fraction provides a syntactic foam with desired structural and mechanical property. In the past, most of the studies have been directed towards mechanical and fracture properties of polymeric matrix syntactic foams under quasi-static or dynamic tension and compression [6-8], flexural [9-11], impact [12,13] or thermal degradation [14].

Structural properties of syntactic foams such as impact resistance have not been explored in details. Composite sandwich panel structures that have syntactic foam as their core are being used in vehicles or airplane fuselage skin. These structures are subjected to low or high velocity impact during their service life due to runway debris, hail impact, maintenance damages (e.g. dropped tools), bird strikes, engine debris, etc. Therefore, a comprehensive study is required to understand the behaviors of these structures under impact loading that has been done in this study.

There are some previous works that investigated on the impact behavior of composite sandwich panels that used crushable foam core like PVC foam [15] or Polyurethane [16] but no one did not used syntactic foam. All of them considered crushing as the only damage mechanism of the core. But, with more precise experimental observation, it has been shown in this study that the foam core damage is partially crushing and partially fracture as a conical plug, especially if a stiff core like syntactic foam is used in sandwich panel.

Although the presence of microballoons in polymeric matrix enhances some mechanical properties but some critical property like specific tensile strength (tensile strength per density) is reduced. So, some 
solution has been suggested to improve this imperfection. In few researches carried out, nanoreinforcing of the matrix material of syntactic foam, enhanced the tensile, compression and flexural properties of syntactic foams [17-19]. Although all of them reported the advantages of introducing nano materials to the polymeric materials, the full potential of nano reinforcing of syntactic foams is not explored enough. In the present study, impact properties of 15 types of syntactic foam core sandwich panel were studied experimentally. High velocity impact tests were carried out with a gas gun and a light blunt head projectile. Matrix material of all fabricated syntactic foams was epoxy. Three sizes of ceramic microballoons with three different volume fractions $(20 \%, 40 \%$ and $60 \%)$ were chosen for fabricating syntactic foams to study the effects of each of these parameters. Nanoclay in five different weight percentages was used in an epoxy matrix to make nanoreinforced syntactic foam. Ballistic limit is measured in the tests and the damaged area is explored carefully. The results are analyzed to study the effect of the volume fraction, the diameter of different microballoons and the nanoclay content on the ballistic limit and extent of failure of sandwich panels.

\section{Experimental Procedure}

\subsection{Materials}

The ceramic microballoons of syntactic foams are supplied from OMEGA MINERALS Germany GmbH with the trade names of SG, WM and W150. Some typical properties of these microballoons are shown in Table 1. Epoxy with the trade name of EPIKOTE 828 from Resolution Performance Products LLC and TETA hardner from Akzo Nobel Functional Chemicals are used for matrix material. EPIKOTE 828 is a medium viscous epoxy resin based on Bisphenol-A. TETA hardner is a low viscous aliphatic amine used for room temperature curing. The resin to hardner ratio specified by the supplier is 10:1. Density of the pure cured epoxy is measured to $1.185 \mathrm{~g} / \mathrm{cm}^{3}$ according to ASTM C271 standard [20].

The nanoclay used is a natural montmorillonite modified with a quaternary ammonium salt that has the trade name Closite 30B, which is manufactured by Southern Clay Products, Inc. Its moisture is less than $2 \%$ and its density is about $1.98 \mathrm{~g} / \mathrm{cm}^{3}$. 
TABLE 1 Structural and mechanical properties of ceramic microballoons.

\begin{tabular}{cccc}
\hline Microballoon type & $\begin{array}{c}\text { Outer diameter } \\
(\boldsymbol{\mu m})\end{array}$ & $\begin{array}{c}\text { Thickness to } \\
\text { radius ratio } \\
(\mathbf{\%})\end{array}$ & $\begin{array}{c}\text { True density } \\
\left(\mathbf{g} / \mathbf{c m}^{\mathbf{3}}\right)\end{array}$ \\
\hline WM & 170 & 10 & 0.7 \\
SG & 130 & 10 & 0.7 \\
W150 & 80 & 10 & 0.7 \\
\hline
\end{tabular}

\subsection{Specimens fabrication}

Plain syntactic foams were fabricated by hand stirring mixing method. Four different volume fractions $0 \%, 20 \%, 40 \%$ and $60 \%$ of microballoons were embedded in epoxy matrix. As the mixing process should be done with cautious because of probable crushing of microballoons, a wooden rod was used to mixing the microballoons and the resin gently. Since the aggregation of microballoons was not seen during mixing, the stirring process was lasted 15 minutes. A full experimental investigation has been carried out about the factors that affect the mechanical properties of syntactic foams $[6,16,19]$. Floatation of microballoons in low volume fractions of microballoons and unwanted porosity (air entrapment in matrix material) in high volume fractions of microballoons, are the most influential factors that should be limited.

To study the effect of nanoclay in reinforcing the syntactic foams, nanoreinforced syntactic foam were fabricated with $40 \%$ volume fraction of W150 microballoons and six different matrix weight percentage of nanoclay $(0 \%, 1 \%, 2 \%, 3 \%, 5 \%$ and $7 \%)$.

The epoxy resin is preheated at $75^{\circ} \mathrm{C}$ for approximately $24 \mathrm{hr}$ in an oven to reduce the viscosity for better wetting of particles. Resin is then removed from the oven and nanoclay is incorporated in the required amount and the mixture is stirred by a mechanical shear mixture at 500 RPM for 30 minutes. After that the mixture is ultrasonicated for 15 minute with the cycle of 0.5 and the amplitude of $60 \%$ [21-23]. During this process, nanoclay clusters break into nanoclay platelets and the resin can penetrate into the nanoclay galleries. During ultrasonication, the temperature rises and a large number of micro-bubbles form. These bubbles are removed from the mixture by degassing and the mixture is cooled down to room temperature. Then the microballoons are added and the mixture is hand stirred until a uniform distribution is insured. Finally, hardner was added to the mixture. 
After mixing, the blend transferred to a stainless steel mould which was smeared with mould releasing agent. The mixture was cured for $48 \mathrm{~h}$ at room temperature.

Composite panels were made by hand lay-up method. When the syntactic foam core cured, $15 \times 15 \mathrm{~cm}^{2}$ specimens were cut by water-jet cutting machine. Then, it was placed between 8 layers of fiber glass woven fabric (4 layers for front skin and 4 layers for back skin). The coating process by resin is carried out layer by layer and finally pressing is applied since the end of curing process ( $24 \mathrm{hrs})$. The aim of applying pressure is to increase the fiber volume fraction of composite laminate and also enhancing the bonding strength between skins and the core.

\subsection{Specimen coding}

Preventing ambiguity about tested specimens, the following nomenclature was used as: PSF-XX-YY. PSF is the abbreviation of Panel with plain epoxy Syntactic Foam core. The name of microballoon is used instead of XX and the volume percentage of microballoon in the epoxy is used for YY. For example, PSF-SG-40 is a syntactic foam with $40 \%$ volume fraction of SG microballoons. Also, for panels with nanoclay syntactic foam, the NSF-XX-Y nomenclature is used. NSF is the abbreviation of nanoclay modified syntactic foam. The volume fraction of microballoons is used instead of XX and the weight percentage of nanoclay in the matrix material is used for Y. For example: NSF-40-5 is a nanoclay syntactic foam with $40 \%$ volume fraction of microballoon and 5\% weight of nanoclay in the epoxy.

\subsection{Impact testing procedure}

The impact tests were conducted at room temperature using a helium gas gun shown in Figure 1. The gas gun consisted of a pressure vessel of 50 bar capacity, a high speed solenoid valve and a stainless steel hollow barrel $4 \mathrm{~m}$ long. The inside diameter of the barrel was $10 \mathrm{~mm}$. The projectiles were blunt cylinders, each weighting $12 \mathrm{~g}$ and about $20 \mathrm{~mm}$ length. The projectiles were hardened so at impact negligible deformations occurred. As shown in Figure 1 the projectile's velocity before impact was measured with a chronograph. The ballistic limit was achieved by impacting panels at different velocities to narrow the range between perforation and no perforation. Generally, the difference between the velocities of perforation and no perforation is very small, so the average of those two velocities is considered as ballistic limit. In this basis, about 8 to 10 specimens were tested to obtain the ballistic limit. 


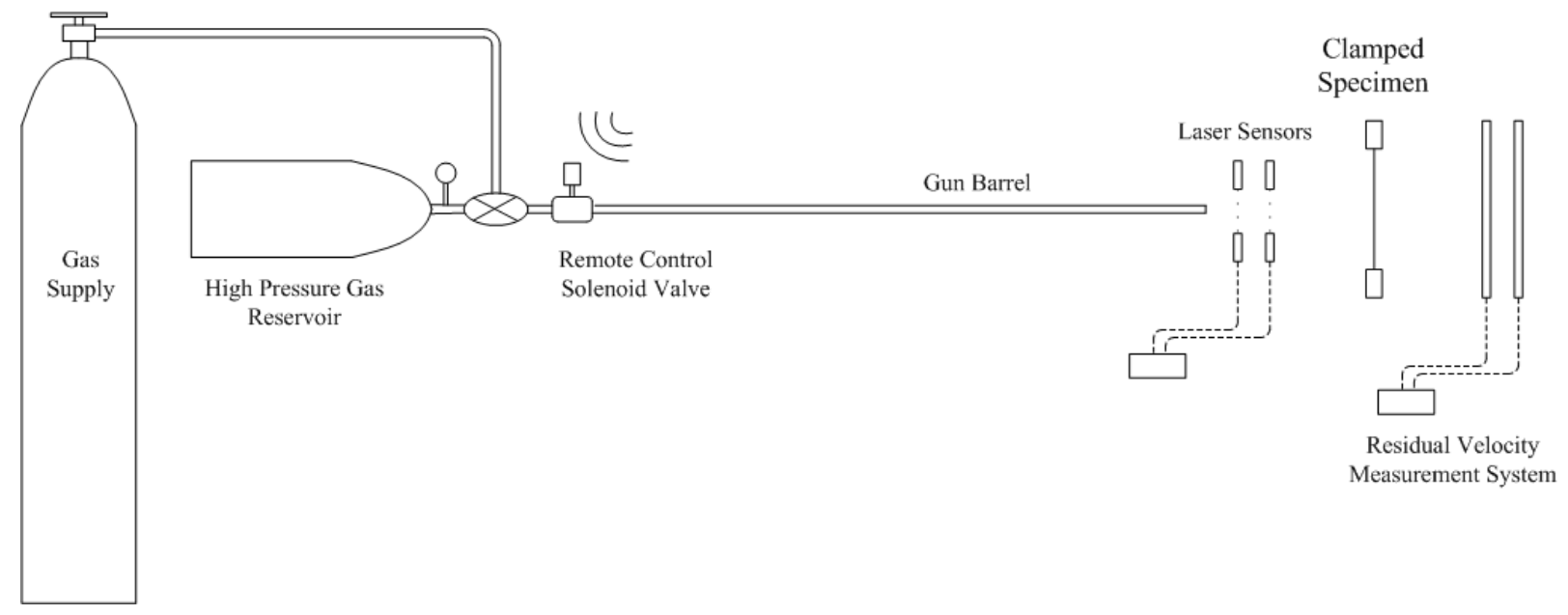

FIGURE 1 Schematic illustration of gas gun ballistic testing setup.

\section{Results and Discussion}

\subsection{Syntactic foam microstructure}

The microstructure of syntactic foam PSF-SG-40 is shown in Figure 2. Broken and crashed microballoons that embedded in epoxy resin can be clearly seen. Along with microballoons, many entrapped air voids were present in the micrograph. These voids constituted the matrix porosity that reduces the foam`s strength. In general, neglecting the matrix porosity, theoretical density of syntactic foams can be calculated using the rule of mixture and assuming nominal values for the constituents' densities:

$\rho_{\text {foam }}=\phi \rho_{m b}+(1-\phi) \rho_{m}$

$\rho_{\text {foam }}$ is the foam density, $\phi$ is the volume fraction of microballoons, $\rho_{m b}$ is the true density of microballoons and $\rho_{m}$ is the density of the matrix.

Experimental densities of the fabricated specimens have been measured according to ASTM standard C271. The weight and volumes of at least five samples of $25 \times 25 \times 13 \mathrm{~mm}^{3}$ cube from each type were measured to calculate the foam density. The matrix porosity is the difference between two densities which calculated by the following equation: 
$\phi_{m}=1-\frac{\rho_{a}}{\rho_{t}}$

$\phi_{m}$ is the volume fraction of matrix porosity, $\rho_{a}$ is the experimental density and $\rho_{t}$ is the theoretical density in this equation.

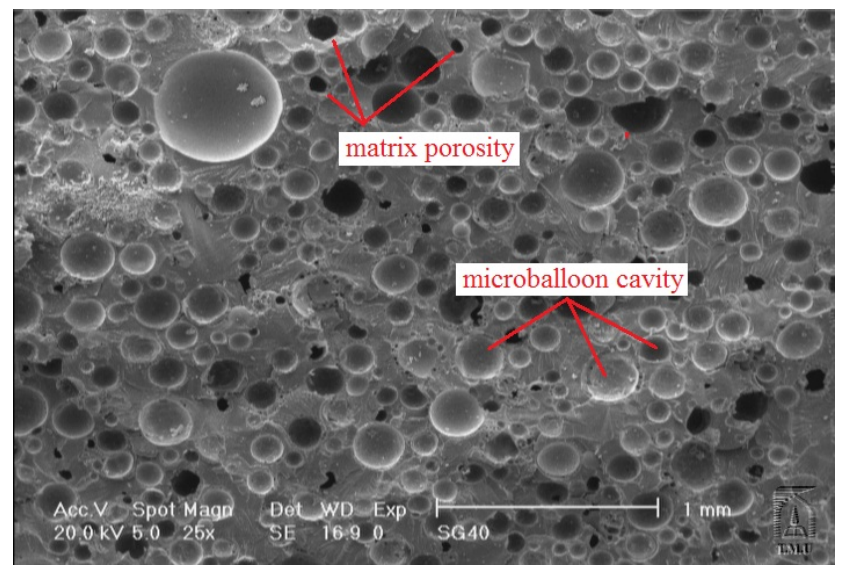

FIGURE 2 SEM image from the fracture surface of the syntactic foam showing matrix porosity.

Table 2 summarizes the results of experimental measurement and theoretical calculations of density for various specimens. It is clear that the matrix porosity content increases as the volume fraction of microballoons increases. The normal matrix porosity can be assumed as $2-5 \%$ as seen in $20 \%$ and $40 \%$ foams. The porosity content of $60 \%$ microballoon volume fraction syntactic foams is about 5 times of $40 \%$ one. The viscosity of mixture before curing is the main detrimental factor that affects porosity value. However, the formation of this type of porosity cannot be controlled completely. It is desired to maintain this type of porosity to a minimum level that does not affect the mechanical properties seriously.

TABLE 2 Structural properties of net epoxy and syntactic foams.

\begin{tabular}{|c|c|c|c|c|c|}
\hline Material & $\begin{array}{l}\text { Volume } \\
\text { Fraction }\end{array}$ & Sample Code & $\begin{array}{c}\text { Measured } \\
\text { Density } \\
\left(\mathrm{g} / \mathrm{cm}^{3}\right)\end{array}$ & $\begin{array}{c}\text { Theoretical } \\
\text { Density } \\
\left(\mathrm{g} / \mathrm{cm}^{3}\right)\end{array}$ & $\begin{array}{l}\text { Matrix } \\
\text { Porosity }\end{array}$ \\
\hline Neat epoxy & 0 & -- & 1.185 & -- & -- \\
\hline $\begin{array}{l}\text { Foam with } \\
\text { SG } \\
\text { microballoon }\end{array}$ & 20 & SF-SG-20 & 1.068 & 1.088 & 1.8 \\
\hline $\begin{array}{l}\text { Foam with } \\
\text { SG } \\
\text { microballoon }\end{array}$ & 40 & SF-SG-40 & 0.969 & 0.991 & 2.2 \\
\hline
\end{tabular}




\begin{tabular}{|c|c|c|c|c|c|}
\hline $\begin{array}{l}\text { Foam with } \\
\text { SG } \\
\text { microballoon }\end{array}$ & 60 & SF-SG-60 & 0.804 & 0.894 & 10.1 \\
\hline $\begin{array}{l}\text { Foam with } \\
\text { WM } \\
\text { microballoon }\end{array}$ & 20 & SF-WM-20 & 1.062 & 1.088 & 2.4 \\
\hline $\begin{array}{l}\text { Foam with } \\
\text { WM } \\
\text { microballoon }\end{array}$ & 40 & SF-WM-40 & 0.962 & 0.991 & 3.0 \\
\hline $\begin{array}{l}\text { Foam with } \\
\text { WM } \\
\text { microballoon }\end{array}$ & 60 & SF-WM-60 & 0.793 & 0.894 & 11.3 \\
\hline $\begin{array}{l}\text { Foam with } \\
\text { W150 } \\
\text { microballoon }\end{array}$ & 20 & SF-W150-20 & 1.046 & 1.088 & 3.8 \\
\hline $\begin{array}{l}\text { Foam with } \\
\text { W150 } \\
\text { microballoon }\end{array}$ & 40 & SF-W150-40 & 0.954 & 0.991 & 3.7 \\
\hline $\begin{array}{l}\text { Foam with } \\
\text { W150 } \\
\text { microballoon }\end{array}$ & 60 & SF-W150-60 & 0.818 & 0.894 & 8.5 \\
\hline
\end{tabular}

Figure 3 shows the X-ray diffraction of nanoreinforced syntactic foams. Maximum peak for nanoclay is at $2 \theta=4.75^{\circ}$. According to the Bragg`s law, the distance between the nano layers would be $18.61 \mathrm{~A}^{\circ}$. As the maximum peak in the diagram decreases, the inter-layer distance will increase. The results of the angles and distances are listed in Table 3. It indicates that the inter layer space was maximum in the nanoreinforced syntactic foam with $3 \%$ nanoclay in the matrix. 


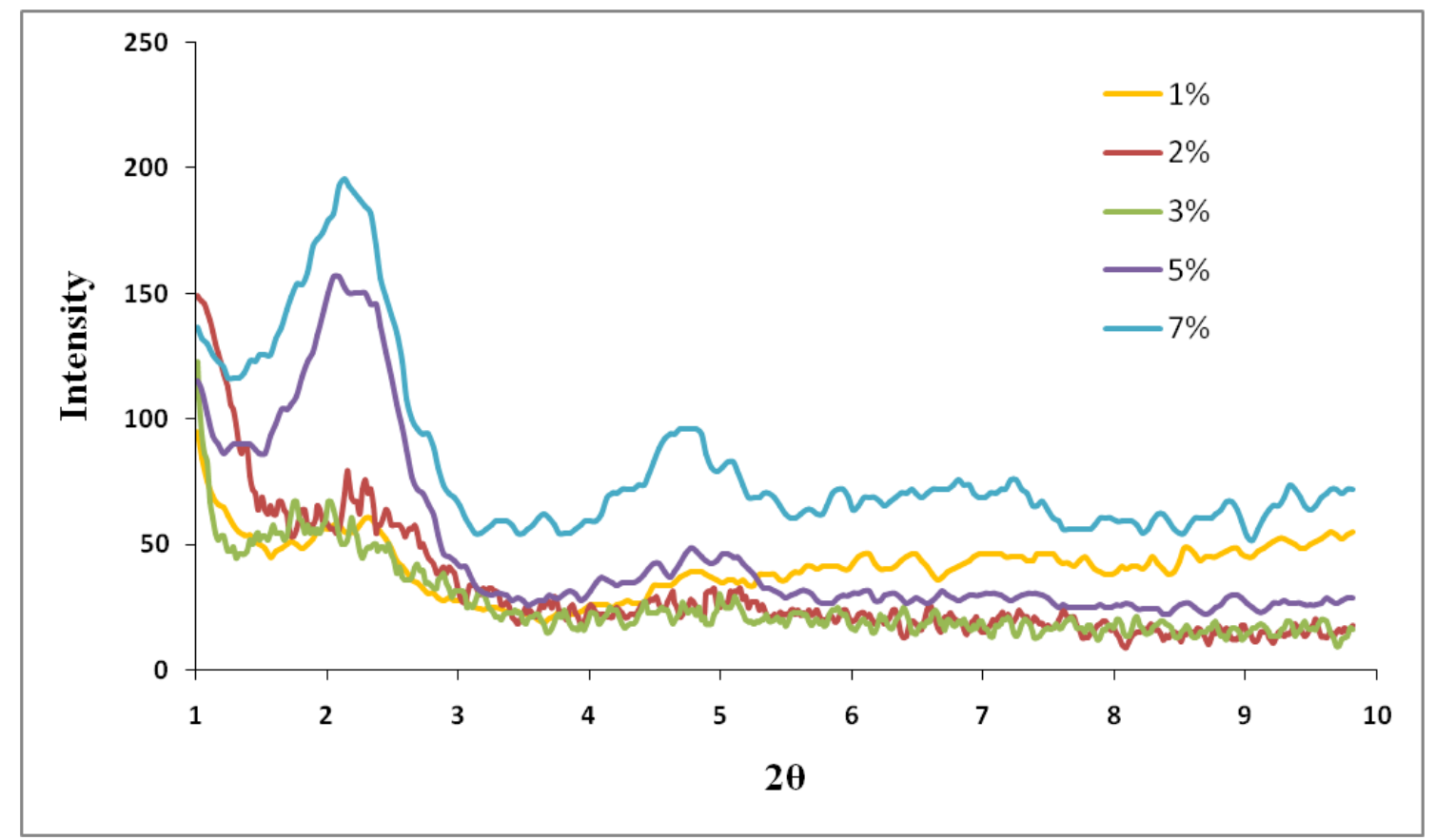

FIGURE 3 X-ray diffraction of different nanoreinforced syntactic foam.

TABLE 3 Inter-layer space of nanoclay layers in different nanoreinforced syntactic foam.

\begin{tabular}{ccccccc}
\hline & Nanoclay & $\mathbf{1 \%}$ & $\mathbf{2 \%}$ & $\mathbf{3 \%}$ & $\mathbf{5 \%}$ & $\mathbf{7 \%}$ \\
\hline $2 \theta\left(^{\circ}\right)$ & 4.75 & 2.16 & 2.08 & 1.88 & 2.19 & 2.09 \\
$\mathrm{~d}$ spacing $(\AA)$ & 18.61 & 40.76 & 42.48 & 54.33 & 42.23 & 40.36 \\
\hline
\end{tabular}

\subsection{Impact behavior}

Fifteen different types of syntactic foam core sandwich panels tested by ballistic impact loading. The ballistic limit was measured and the panels were explored thoroughly to determine the failure mechanisms. Figure 4 shows the front and rear faces of an impacted panel. A plug was formed from the front skin about the size of the head of blunt projectile and also, the debonding between skin and the foam core was propagated to boundaries. The failure at the rear skin was fiber fracture of the laminate. The failure area in the front and rear skin was aligned and about the size of projectile diameter. This indicates that the perforation process occurred in a straight line and there is no off-axis rotation of the projectile. 


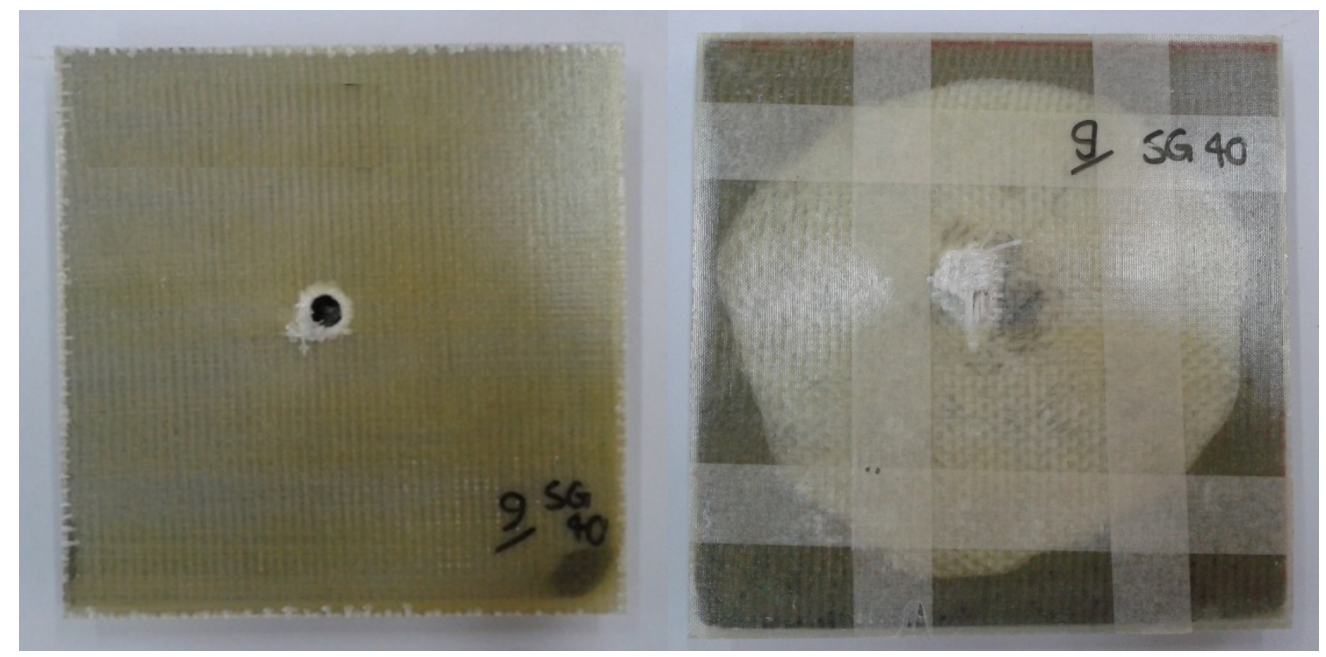

(a)

(b)

FIGURE 4 (a) Front and (b) rear skin of the target after ballistic test.

Figure 5 shows the failure of the cores of sandwich panels for PSF-SG-20, PSF-SG-40 and PSF-SG-60 specimens. In all of the specimens, the failure area is like a truncated cone. Except the net epoxy core that the radial and circumferential cracks propagate near the boundaries, in the others the cracks limited to the plug area. The plug did not remain intact and pulverized to smaller pieces. As the more microballoon content, the more pulverization and smaller pieces which the plug of the foam with $60 \%$ volume fraction became powder. Detachment of the truncated cone plug and its pulverization absorbed considerable amount of energy. Bigger plug had more crack surfaces and absorbed more energy. On the other hand, the more pulverization of smaller plugs compensated their smaller cracks partially.

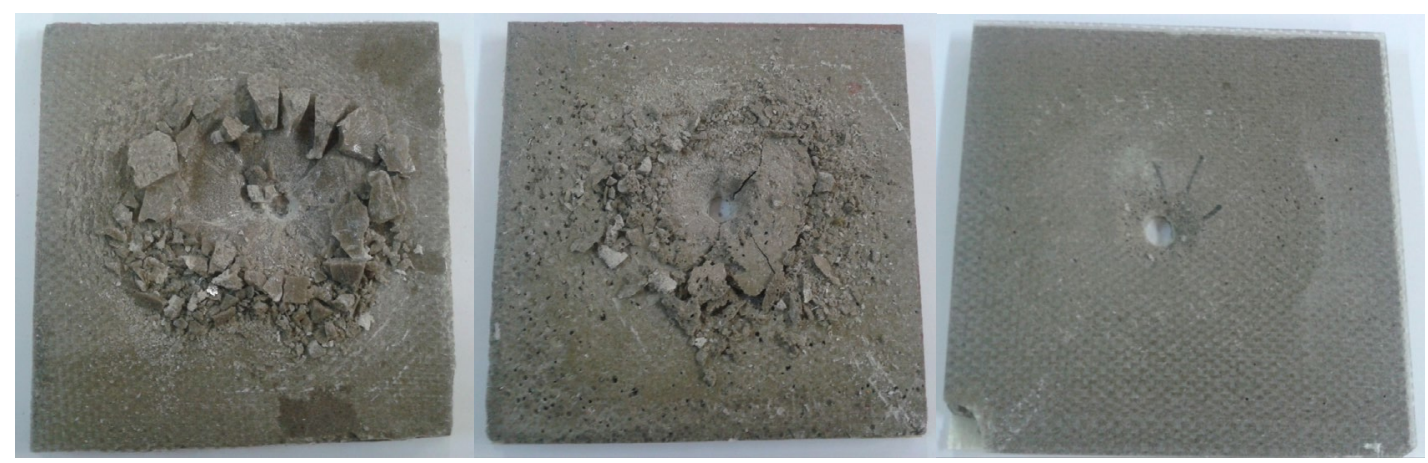

(a)

(b)

(c)

FIGURE 5 Failure of the core of sandwich panels in their rear face (a) PSF-SG-20, (b) PSF-SG-40 and (c) PSF-SG-60. 
When the projectile impacts the panel, the foam ahead of the projectile crushes locally and indentation before forming the plug is occurred. Figure 6 shows the schematic of the conical plug and its dimension. When the projectile impacted the target, partially penetrated into it and created a hole of the size of the projectile. The syntactic foam just in front of the projectile is crushed and accumulated. By further penetration the contact force between the projectile and the target increased to form the progressive oblique through thickness crack and a conical plug was formed. The observations indicate that in all of the tested specimens, the smaller face of the plug was nearly equal to the blunt head, but its rear face and height was changed with various microballoon content.

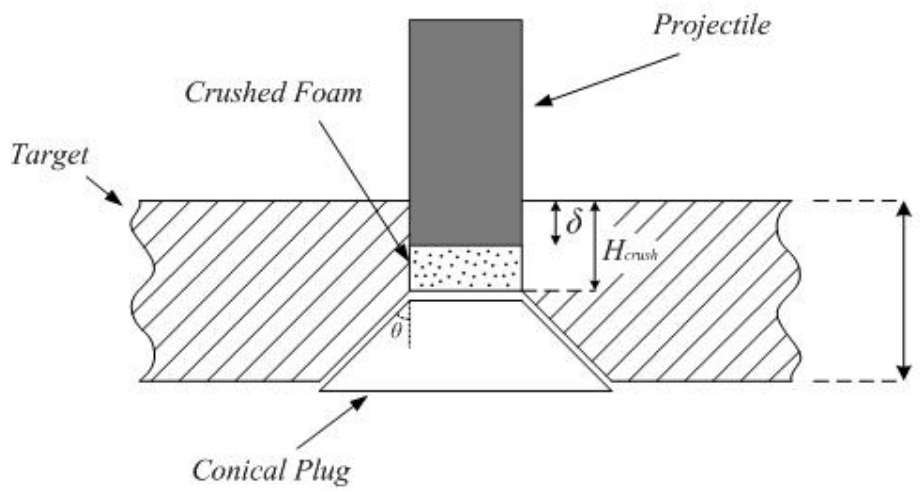

(a)

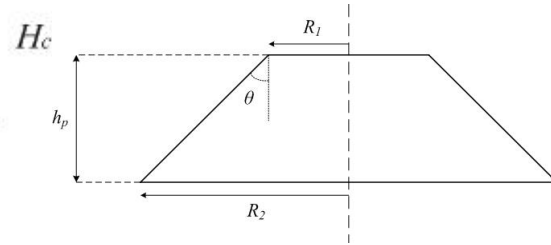

(b)

FIGURE 6 Schematic diagram of the conical plug, (a) fracture pattern of the core, (b) dimension of the conical plug.

Dimensions of the different plugs are shown in Table 4. As explained before, the results show that the projectile indented the foam core partially just before the conical plug detaching. The length of the indentation depends directly on the volume fraction of microballoon content in the foam. As the volume fraction of the microballoon increases the compressive strength of the foam decreases [6]. As a result, the resistance of the foam against perforation by the projectile decreases too. This is obvious as the crush length of the foams with $0 \%, 20 \%$ and $40 \%$ microballoons volume fraction increases.

TABLE 4 Dimensions of the conical plug of different syntactic foam core.

\begin{tabular}{cccccc}
\hline $\begin{array}{c}\text { Syntactic } \\
\text { Foam Core }\end{array}$ & $\begin{array}{c}\mathbf{R}_{1} \\
(\mathbf{m m})\end{array}$ & $\begin{array}{c}\mathbf{R}_{2} \\
(\mathbf{m m})\end{array}$ & $\begin{array}{c}\mathbf{H}_{\mathbf{C}} \\
(\mathbf{m m})\end{array}$ & $\begin{array}{c}\mathbf{H}_{\text {crush }} \\
(\mathbf{m m})\end{array}$ & $\begin{array}{c}\boldsymbol{\theta} \\
(\text { degree })\end{array}$ \\
\hline
\end{tabular}




\begin{tabular}{cccccc}
\hline epoxy & 5.0 & 33.4 & 11.2 & 0.0 & 68.5 \\
SF-SG-20 & 5.0 & 20.1 & 11.1 & 3.0 & 61.7 \\
SF-SG-40 & 5.0 & 16.8 & 11.0 & 4.0 & 59.5 \\
SF-SG-60 & 5.0 & 13.5 & 11.0 & 4.0 & 50.8 \\
\hline
\end{tabular}

As shown in table 4 , the crush length of $60 \%$ microballoon volume fraction is equal to the foam with $40 \%$ microballoon volume fraction. The reason would be related to less shear strength of the foam at higher microballoons content. Actually, after partial penetration into the foam, the shear cracks are formed and truncated cone plug detached.

One of the important properties of the cone plug is the cone angle shown as $\theta$ in Figure 6 . Although $\theta$ is decreased with increasing the microballoon content, it can be estimated about $60^{\circ}$ as reported elsewhere [24].

According to the observations and results, the perforation process into the targets of syntactic foam core sandwich panels can be explained as below. As the projectile strike the target, punch the front skin and a plug equal to the blunt head would be cut out. By further penetration, because of bending and flexural loading, the target deforms and some strain energy would be absorbed. During the process, the contact force between the projectile head and the target increases, and causes local crushing ahead of the projectile and simultaneously creating shear stresses between skin layers and also between the skin and the core. When these stresses attain the critical value, progressive delamination in skin composite laminate and also debonding of skin and core will occur. It should be noted that during the projectile perforation, friction between the peripheral surface of the projectile and the target dissipate energy of the projectile and decrease its velocity.

With increasing projectile penetration, the target deforms more and the absorbed energy increases. In addition, the failure mechanisms progressively spread and gradually absorb kinetic energy of the projectile.

Detaching the plug from the core is directly related to the magnitude of contact force between the projectile head and the target. The contact force increases as the penetration of the projectile progresses. When the contact force reaches to the shear strength of foam core, the conical plug cuts out and separates 
from the core, crushed between the projectile and rear skin, and becomes pulverized. This plugging and pulverization absorbs significant amount of energy.

After core plugging, the projectile and the plugs exert force on the rear skin and cause deformation of the skin in bending and stretching. When the strain of the fibers at the edge of the projectile reaches to its critical value, fiber fracture occurs and the projectile with plugs exit out.

Based on the explained perforation process of projectile, different failure and energy absorbing mechanisms that dissipate projectile's energy are:

a. Plugging of the front skin

b. Delamination of composite laminates of the skin

c. Debonding between skins and core

d. Local core crushing ahead of projectile and partial penetration

e. Plugging of the core and its pulverization

f. Fiber fracture of the rear skin

g. Friction between the projectile and the target

h. Global deformation of the target and absorbing energy as strain energy

i. Moving of target constituents and absorbing energy as kinetic energy

\subsection{Ballistic limit velocity}

The charts in the Figures $7 \& 8$ show the ballistic limit velocity and the specific perforation energy (measured absorbed energy per areal density of the specimen) of different syntactic foam core sandwich panels. The results show that regardless of microballoon type by increasing the microballoon content in the syntactic foam core, the ballistic resistance of the panel decreases. Plugging of the core and its pulverization absorb a major part of the projectile`s energy. This failure mechanism is directly depending on tension and compression strength of the foam core. By increasing the microballoon volume fraction, the tension and compression strength decreases and consequently the ballistic resistance decreases [6]. However, in light weight composite materials, the properties should be considered relative to their weight. The results of previous research [6] show that, although the specific tension strength decreases by increasing microballoon volume fraction, but specific compression strength and specific elastic modulus increases. These are the major properties that affect the ballistic resistance and they are in conflict. 
Overall, the results show that the specific perforation energy increases up to $8 \%$ for PSF-SG- 40 . The specific properties of syntactic foam with $60 \%$ volume fraction are less than $40 \%$ volume fraction [6]. As a result, the specific perforation energy would be reduced.

The size of microballoon has a considerable effect on the ballistic strength of the panels. The results indicate that by decreasing the diameter of the microballoons, the ballistic strength would enhance up to $10 \%$.

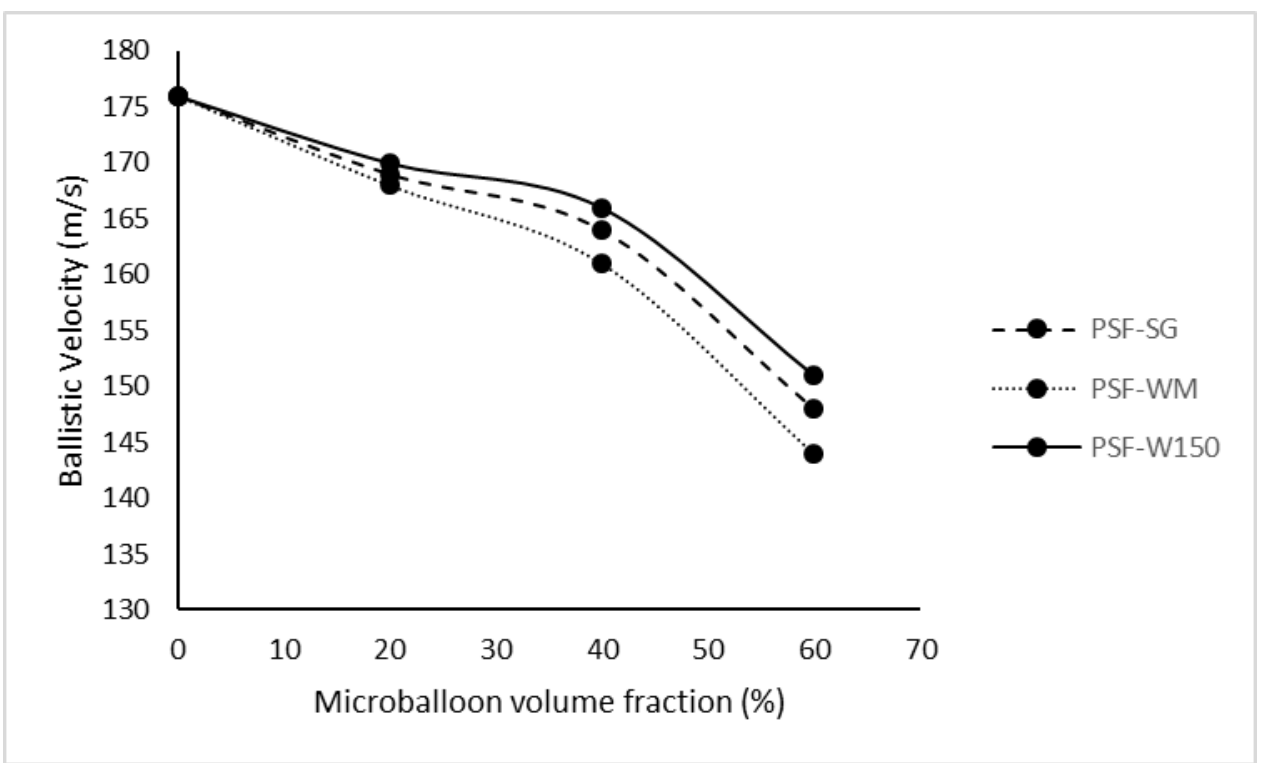

FIGURE 7 Ballistic limit velocity of different syntactic foam core sandwich panels. 


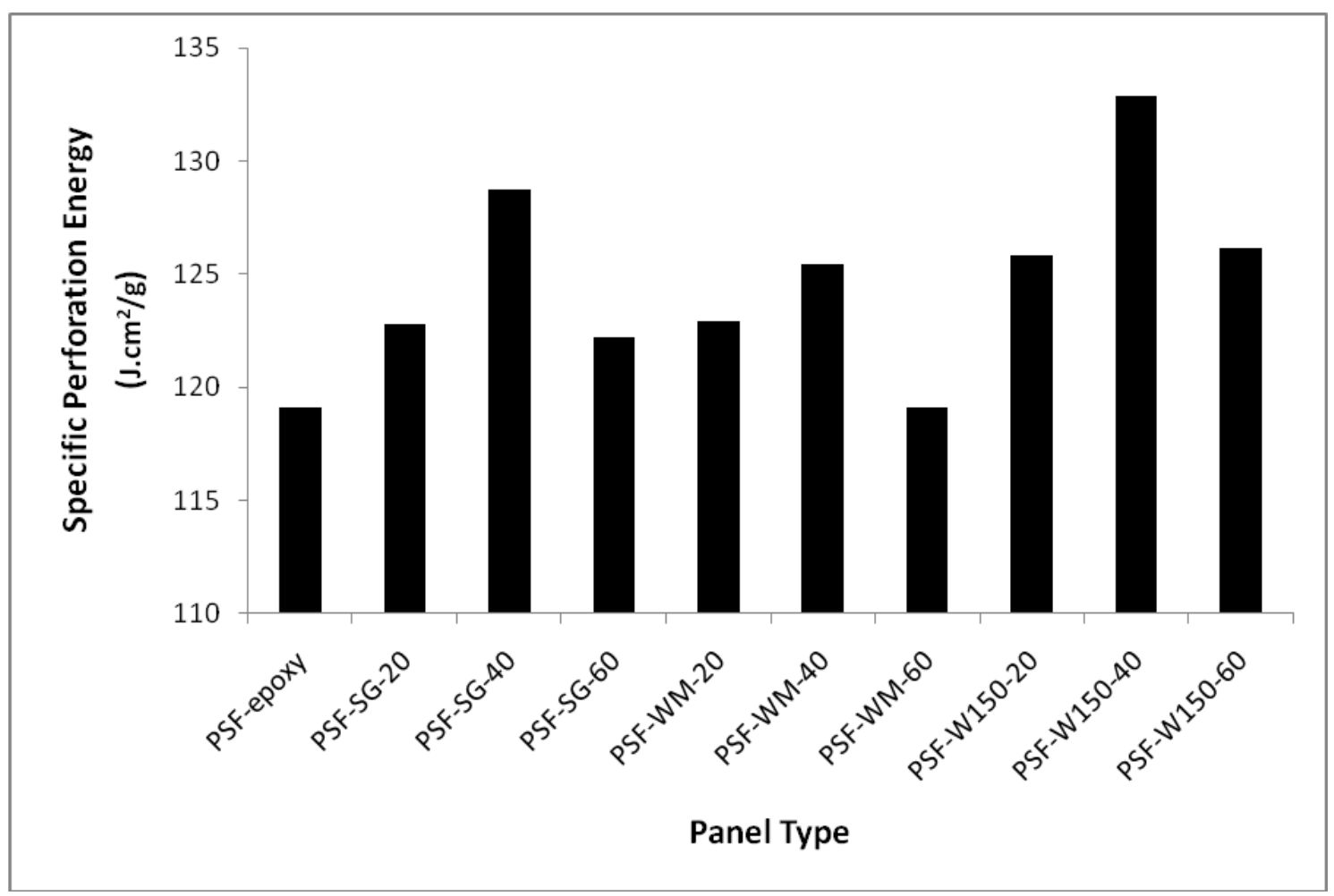

FIGURE 8 Specific perforation energy of different syntactic foam core sandwich panels.

\subsection{Effect of nanoreinforcing}

The results of ballistic tests on the 6 type of nanoreinforced syntactic foam core sandwich panel are shown in Figure 9. As the nanoclay content increases in the foam, the ballistic resistance increases, too. The maximum increase in perforation energy was about $10 \%$ for the foam with $3 \%$ weight fraction of nanoclay. Increase in strength show that the nanoclay platelets have been dispersed well. In this case the matrix molecules penetrate between the platelets and because of good adherence of nano particles to matrix, a large number of interfaces are created in the matrix. Therefore, nano particles bear some parts of the load and the strength of material increases.

Increasing the nanoclay content more than $3 \%$ resulted in decreasing the strength drastically. When the nano particle content increases, the number of interfaces becomes more that results to form agglomeration of nanoclay platelets [22]. The agglomeration is considered as an imperfection and can ease the crack propagation. 


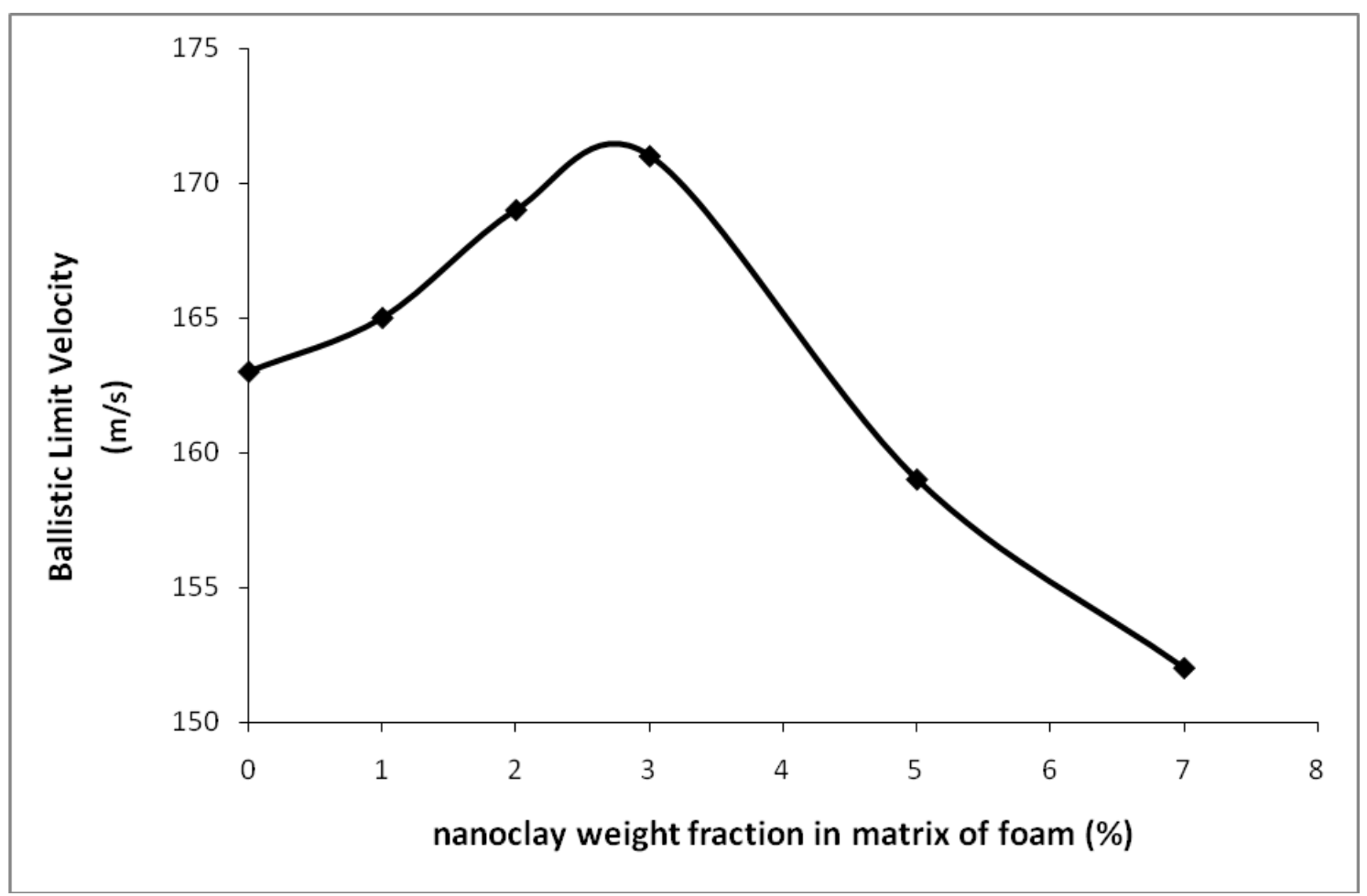

FIGURE 9 Ballistic limit velocity of different nano syntactic foam core sandwich panels.

\section{Conclusions}

In this paper the impact behavior of the panels with plain and nanoreinforced syntactic foam core is investigated. The effective factors like microballoon volume fraction and the diameter of microballoon were studied thoroughly and quantitatively. The results show that by increasing the microballoon volume fraction, the ballistic resistance decreases but the specific perforation energy increases and its amount is highest for the panel with foam core containing $40 \%$ volume fraction of microballoon. Also, the results show that by decreasing the size of microballoons, the ballistic resistance would enhance up to $10 \%$.

The failure mechanisms in the panel were observed and categorized. Plugging of the front skin, delamination of composite laminates, debonding between skins and core, local core crushing and partial penetration, plugging of the core and its pulverization and fiber fracture of the rear skin were the most important failure mechanisms of these composite sandwich panels. Because of the skins are thin, truncated cone plugging and core crushing are the dominant mechanisms of energy absorption by the projectile perforation. One of the advantages of syntactic foam is the limited failure area by the impact loading, which is responsible for the more post impact resistance of the panel. 
The effect of addition of nanoclay in the matrix of the syntactic foam was also investigated. The results show that presence of $3 \mathrm{wt} \%$ of nanoclay enhances the ballistic resistance about $10 \%$. Increasing nanoclay content more than $3 \%$ results in agglomeration phenomenon and the ballistic resistance drastically decreases.

\section{Funding}

This research received no specific grant from any funding agency in the public, commercial, or not-forprofit sectors.

\section{Conflict of Interest}

The authors declare that they have no conflict of interest.

\section{References}

1. Shutov FA. Syntactic polymer foams. In: Sendijarevic V, Klempner D, editors. Handbook of polymeric foams and foam technology, New York: Hanser Publishers; 2004, p. 479-504.

2. Winer A. Syntactic Flotation Material for Deep Submergence Vehicles. J Cell Plast 1966, 2: 157-161.

3. Kumar SA and Ahmed KS. Compression behavior and energy absorption capacity of stiffened syntactic foam core sandwich composites. J Reinf Plast Compos 2013; 32: 1370-1379.

4. Weiser E S, Johnson T F, St Clairt T L, Echigo Y, Kaneshiro H, Grimsley B W. Polyimide foams for aerospace vehicles. High Perform Polym 2000, 12: 1-12.

5. Anderson TF, Walters HA and Glesner CW. Castable, Sprayable, Low Density Foams and Composites for Furniture, Marble, Marine, Aerospace, Boats and Related Applications. J Cell Plast 1970; 6: 171-178.

6. Ahmadi H, Liaghat G H, Shokrieh M M, H Hadavinia, A Ordys, A Aboutorabi. Quasi-Static and Dynamic Compressive Properties of Ceramic Microballoon Filled Syntactic Foam, J Compos Mater 2015, 49: 1255-1266. 
7. Gupta N, Sankaran S. On the Characterisation of Syntactic Foam Core Sandwich Composites for Compressive Properties. J Reinf Plast Compos 1999; 18: 1347-1357.

8. Song B, Chen W, Frew D J. Dynamic compressive response and failure behavior of an epoxy syntactic foam. J Compos Mater 2004; 38: 915-936.

9. Karahan M, Gul H, Karahan N, et. al. Static behavior of three-dimensional integrated core sandwich composites subjected to three-point bending. J Reinf Plast Compos 2013; 32: 664-678.

10. Gupta N and Woldesenbet E. Characterization of Flexural Properties of Syntactic Foam Core Sandwich Composites and Effect of Density Variation. J Compos Mater 2005; 39: 2197-2212.

11. Woldesenbet E and Sankella N. Flexural properties of nanoclay syntactic foam sandwich structures. J Sand Struct Mater 2009; 11: 425-444.

12. Paul D, Ramachandran V, Gupta N K. Improvements in the crushing behaviour of glass fibreepoxy composite tubes by the addition of hollow glass particles. Thin-Walled Structures 2019, 141: 111-118.

13. Kim H S, Mitchell C. Impact performance of laminates made of syntactic foam and glass fiber reinforced epoxy as protective materials. J. Appl. Polym. Sci. 2003; 89, 2306-2310.

14. Qiao Y, Wang X, Zhang X, et al. Thermal conductivity and compressive properties of hollow glass microsphere filled epoxy-matrix composites. J Reinf Plast Compos 2015; 34: 1413-1421.

15. H. M. Wen, T. Y. Reddy, S. R. Reid, S. R. Soden. Indentation, penetration and perforation of composite laminates and sandwich panels under quasi static and projectile loading. Key Eng Mat 1998, 141: 501-552.

16. R. Nasirzadeh, A. R. Sabet. Study of foam density variations in composite sandwich panels under high velocity impact loading. Int J Impact Eng 2014, 63: 129-139.

17. Gupta N, Maharsia R. Enhancement of energy absorption in syntactic foams by nanoclay incorporation for sandwich core applications. Appl Compo Mater 2005; 12: 247-261.

18. H Ahmadi, GH Liaghat, MM Shokrieh, A Aboutorabi, H Hadavinia, A Ordys. Compressive properties of nanoclay-reinforced syntactic foams at quasi-static and high strain rate loading. Polymer-Plastics Technology and Engineering 2014, 53 (10): 990-999.

19. H Ahmadi, GH Liaghat, H Hadavinia. Investigation on tensile properties of plain and nanoclay reinforced syntactic foams. International Journal of Composite Materials 2016, 6 (1): 34-41. 
20. ASTM Standard C271. Standard test method for density of sandwich core materials. ASTM International 2004, West Conshohocken, PA, USA.

21. A Afrouzian, H Movahhedi Aleni, GH Liaghat, $\mathrm{H}$ Ahmadi. Effect of nano-particles on the tensile, flexural and perforation properties of the glass/epoxy composites. Journal of Reinforced Plastics and Composites 2017, 36 (12): 900-916.

22. García C, Fittipaldi M, Grace L R. Effect of nanoclay content on nanoclay dispersion mechanism: Diffusion-controlled mechanism versus shear-controlled mechanism. J Reinf Plast Compos 2013; 32: 1956-1965.

23. T.-D. Ngo, M.-T. Ton-That, S. V. Hoa and K. C. Cole. Reinforcing effect of organoclay in rubbery and glassy epoxy resins, part 1: Dispersion and properties. J. Appl. Polym. Sci. 2008; $107,1154-1162$.

24. Carlucci D E and Jacobson S S. Ballistics theory and design of guns and ammunition. Boca Raton: CRC Press, 2008, p. 313-351. 